\title{
Life Saver Using Raspberry Pi
}

\author{
Akshaya V Madhu', Anju mol John' ${ }^{2}$, Aswathy Jayakumar ${ }^{3}$, Aswathy B Nair ${ }^{4}$, Neena G Krishnan ${ }^{5}$ \\ ${ }^{1,2,3,4}$ Student, Department of Computer Science and Engineering, \\ Mangalam College of Engineering, INDIA \\ 12akshayavmadhu@gmail.com² johnanju1997@gmail.com, \\ ${ }^{3}$ aswathyjaykumar1997@gmail.com, ${ }^{4}$ aswathybnair42@gmail.com \\ ${ }^{5}$ Assistant Professor, Department of Computer Science and Engineering, \\ Mangalam College of Engineering, INDIA, neenagkrishnannadanam@gmail.com
}

\begin{abstract}
Life saver using raspberry pi system is proposed to bring back the critical patients to life. It makes a good communication link between donor and recipient in the same platform. Those who are ready to provide blood, eye and kidney should register in this application and this information can be kept in the database. Any emergency situation, the patients can access through this application and the request can fulfill by using the raspberry pi and IoT.
\end{abstract}

Key words: Raspberry pi, IoT

\section{INTRODUCTION}

Every year, the demand of blood and other organs are increasing. Donation is to protects breathes that would then be gone. For majority of patients, this is the best option. It can help you to live longer and with a better quality of life.

To enable another person obtained vision is one of the best forms of charity. Eyes from a passed on individual can allow two blind individuals to obtain vision. Every year thousands of individuals hurt from corneal blindness whether from sickness or injury. Eye contribution can support these persons recover their vision and live a more enjoyable life.

Blood contribution is the most important that a person can create to the society. Every day, blood transfusion can yield place and protect the breathes of numerous publics all up the world. Contributing blood can support in giving patients pain from cancer. It is significant to see that human blood cannot be manmade, people are the one source of it and that is why it is significant to contribute blood and 'those who need it.

If single person is hurt from end stage kidney disease, he or she can be handled by two common options: dialysis and kidney transplantation. If kidney failure patients get kidney transplant well, they can lead a normal life.

A lifesaver system replaces manually update to process, here will design an advanced android application. so whoever wants to provide the blood and the organ can update their details through this app, and that particular information will be stored in the database whereas the blood and the organ required person will request through telegram app and system will search the database and send the location of the requester to the registered donors. This life saver brings the voluntary blood donors and persons in need of blood on to a same place. "Direct contact between the donor and the recipient within a limited time" is the main concept of the system. Telegram app based routing is the technique used for given that the relationship between the contributor and recipient.

\section{LITERATURE REVIEW}

To accomplish every blood request by using an SMS based GSM module. The main aim is to propose this project is to shrink the time span between the donor and recipient. By using Raspberry Pi B+ and GSM modem SIM900A, i gather all the data base of the unpaid students blood donor information from all the organization and obtain the given data as per message request from recipient [1].With Raspberry pi 2 and GSM modem SIM900A, we gather every data base of the controlled student's blood contributor information starting from educational institution and get the known information as per message ask for from receiver. The fetch blood giver facts is send to the receiver and also by means of adding an IP Address is attach to the message which allow the receiver to download an app and find all the in turn of the student [2].The future effort explore to discover blood donor by means of GSM base Smart Card CPU -Raspberry Pi $\mathrm{B}+$ Kit. The dream is to be "The hope of every Indian in search of a voluntary blood donor" [3].Only a register one with enthusiasm to ' give blood, will be clever to right of entry to the service. In this application we are use the GPS knowledge that will be use to draw the method to the blood bank. The user will get the way to arrive at the needed place and he won't have to enquire by hand, therefore moment can be save [4]. A blood bank is blood components collect as a effect of blood support or group, deposited and preserved for future use in blood transfusion. The task is to complete each blood request in the rural area with a promise SMS application and encouraged persons who are willing to contribute blood [5]. The system will arrange the similar blood contributor and blood giver information is send to the 
receiver and Email is attach to the receiver .To shrink the time period among the giver and receiver [6].

\section{PROPOSED SYSTEM}

Here we will strategy progressive android mobile application using raspberry pi and iot for publics who are agreeable to contribute blood and other organs.

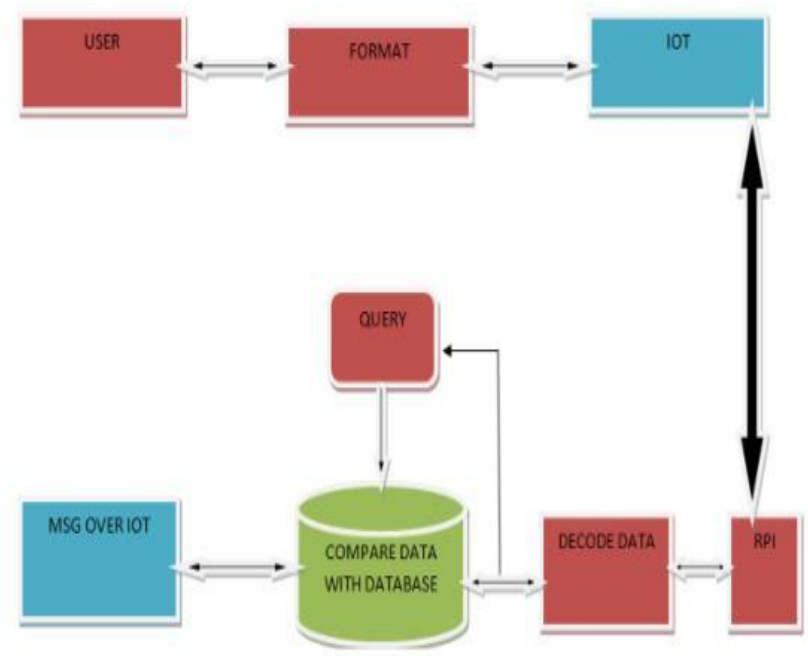

Figure 1: Proposed system

The proposed system is to discover who are keen to donate blood, kidney and eye givers by using IoT and raspberry pi. In the system resides of android application, IoT and raspberry pi. Person who desires to donate blood is needs to catalogue in the android application. And this information will be stored in the database Application spectacles three different screens such as Register, Query and about us. Contributor need to register his/her detail. Patients need to select vital blood group or mandatory organ in the query. Then that information will read from database and message will be send to the contributor through IoT and hence there will be straight communication among donor and patient.

- Subscriber who wishes to donate blood, kidney and eye needs to register his data.

- This data will be deposited in database.

- User in necessity of blood, kidney and eye will have to select mandatory blood group and address.

- Corresponding donor's details will be gotten and exhibited on screen.

- Patient desires to select donor and sent message possibility on the screen.

- Message will be conduct to the matching donor directly through IoT.

\section{EXPERIMENTAL RESULT}

The life saver using raspberry pi system will seek out all the database and send the place of the client to the registered donor's .This life saver bring chosen contributor and persons in need of organs on to a common platform.
Straight contact between giver and the receiver is the major idea. Organ donation can save a person's life. Telegram app routing is a technique used in this system.

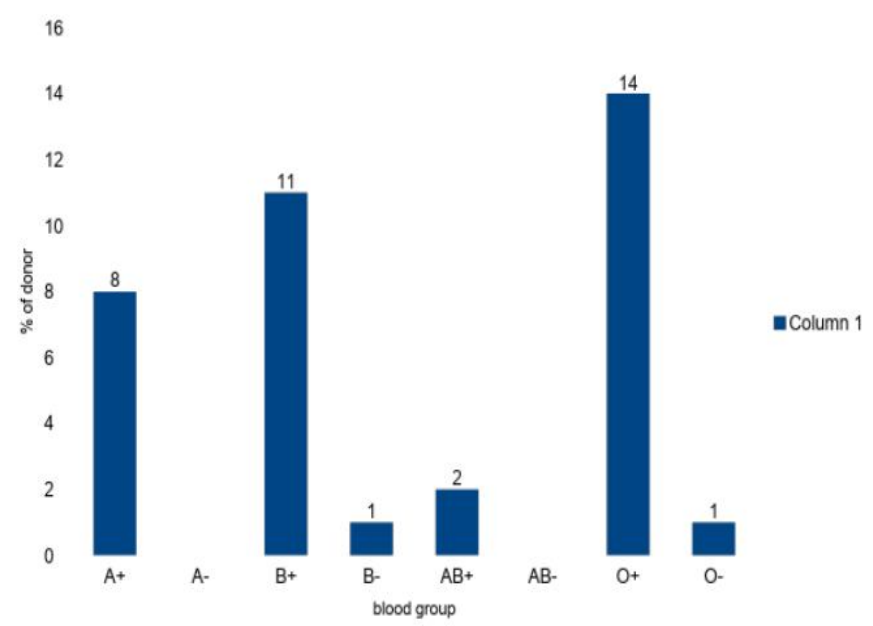

Figure 2: Percentage of donor's

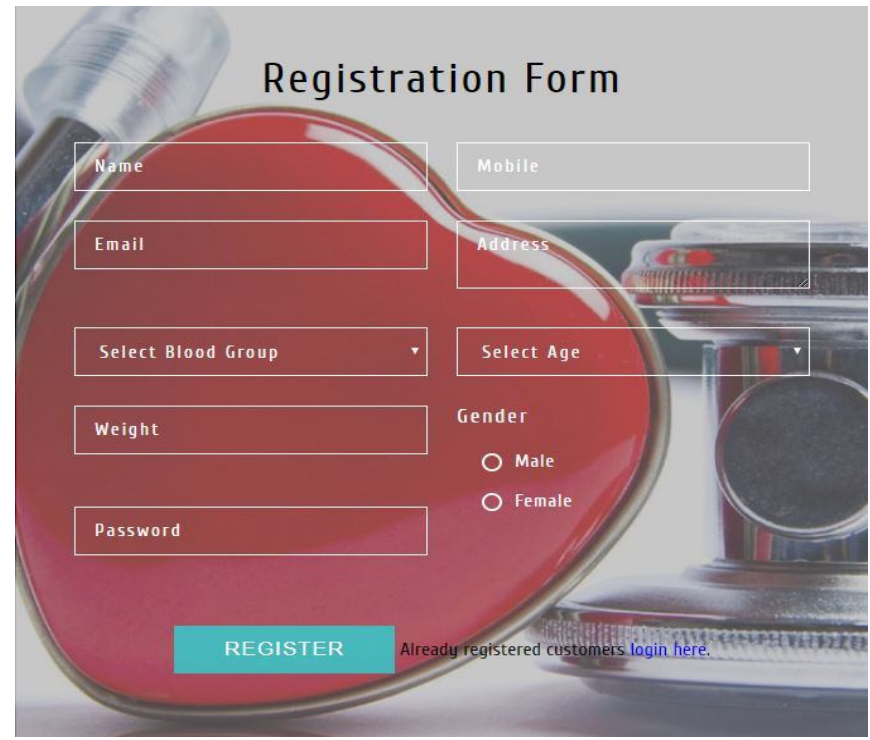

Figure 3: Registartion Form

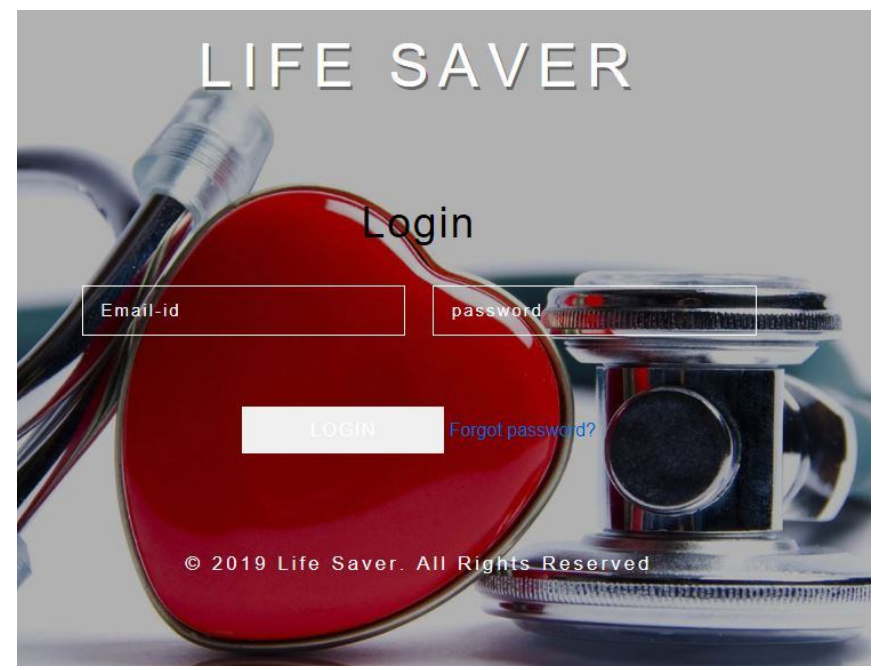

Figure 4: Login 


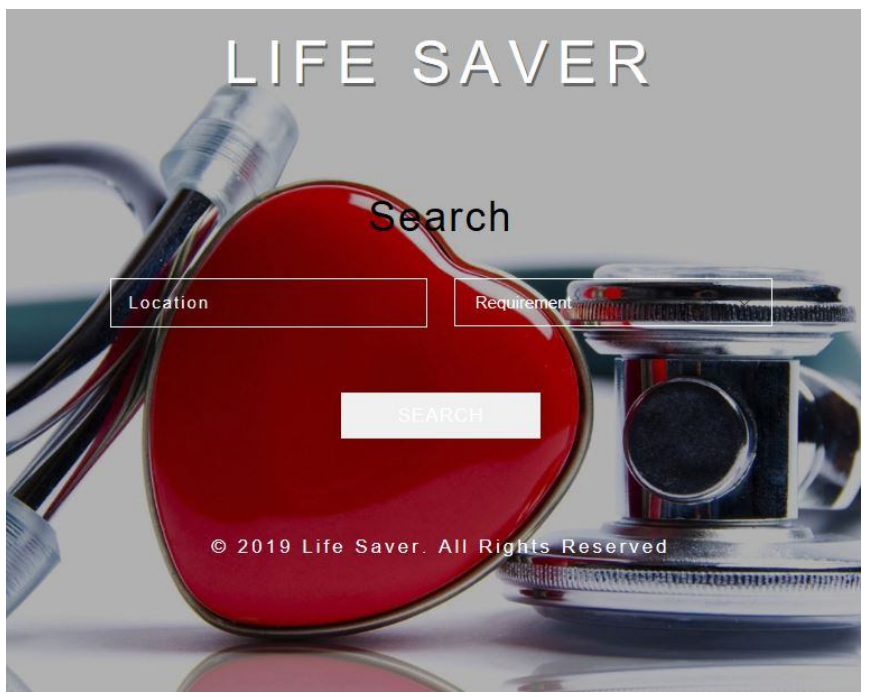

Figure 5: Search

\section{CONCLUSION}

This project aims to reduce the time span between the donor and the recipient. It is IoT based and Using android application and raspberry pi. This is straight message between donor and Recipient through telegrams application.

Wants to offer the blood and other organs (eye and kidney) can fill in their details through this application. If someone can donate can update their details through this app, and the particular information will be store in the database, whereas blood and organ required person will request through telegram app. This system will search all the databases and send the location of the client to the registered donor's . This life saver brings voluntary donors and those in need of organs on to a common platform. Direct contact between donor and the recipient is the main concept. Organ donation can save a person's life. Telegram app routing is a method used in this system.

\section{REFERENCES}

1. T.Gayatri Devi, G.Vijay Kumar, "Automated Blood Donating And Managing System Using Raspberry Pi B+", SSRG International Journal of Computer Trends and Technology (IJCTT) - Special Issue - April 2017.

2. M. Geetha Pratyusha, P.V.V.N.D.P. Sunil, K. Tejaswi, P.Kanakaraja , Y.RamyaSree ,"Raspberry-Pi Based Embedded Blood Donating Application", International Journal of Innovative Research in Science, Engineering and Technology, Vol. 5, Issue 4,April 2016.

3. Bala Senthil Murugan L, Anitha Julian, "Design and Implementation of Automated Blood Bank using Embedded Systems", IEEE Sponsored 2nd International Conference on Innovations in Information, Embedded and Communication systems(ICIIECS)2015, 978-1-4799-6818-3/15.
4. Prof. Snigdha, Varsha Anabhavane, Pratikshalokhande, SiddhiKasar, Pranita More ,“Android Blood Bank”, International Journal of Advanced Research in Computer and Communication Engineering Vol. 4, Issue 11, November 2015.

5. Miss. Pooja a. Taywade, prof. Ajay p. Thakare, "a survey on implementation of SMS (short messaging service)based automated blood bank using raspberry pi for rural areas", international journal of pure and applied research in engineering and technology, Volume 4 (9): 628-635, IJPRET, 2016.

K.SRILEKHA1, SHRUTHI DASARI ,'Blood Bank System using RPI", International Journal of Scientific Engineering and Technology Research, Pages-5424-5427,Volume-05,Issue-27,Vol.05,Septembe r-2016. https://doi.org/10.15623/ijret.2016.0505052 